\title{
MoDELS 2006 Doctoral Symposium
}

\author{
Gabriela Arévalo ${ }^{1}$ and Robert Pettit ${ }^{2}$ \\ ${ }^{1}$ LIRMM - Université de Montpellier II, France \\ Gabriela.Arevalo@lirmm. fr \\ ${ }^{2}$ The Aerospace Corporation, USA \\ rob.pettit@aero.org
}

\section{Doctoral Symposium Overview}

The Doctoral Symposium at the MoDELS conference provided an international forum for doctoral students to interact with other students and faculty mentors. The Doctoral Symposium sought to bring together $\mathrm{PhD}$ Students working in areas related to modeling and model-driven engineering. Selected students had the opportunity to present and to discuss their research goals, methods and results within a constructive and international atmosphere. The goal of the symposium was to provide useful guidance for completion of the dissertation research and initiation of a research career. The symposium was intended for students who have already settled on a specific research proposal and have some preliminary results, but still had enough time remaining before their final defense so that they could benefit from the Symposium discussions. Fifteen $\mathrm{PhD}$ students from different countries submitted papers to the symposium. Submissions were judged on originality, overall contribution, technical merit, presentation quality and relevance to the conference topics. Each submission was reviewed by one mentor from the senior program committee. Of the fifteen $\mathrm{PhD}$ submissions, seven students were invited to present their work at the symposium. To motivate the interaction between the participants, each student that was invited to attend was assigned a specific mentor to be in charge of leading the discussion after the student's presentation, and a specific mini-mentor (another $\mathrm{PhD}$ student) to contribute additional questions.

We would like to thank the members of the doctoral symposium panel for their work in reviewing the students' submissions, and for participating in the symposium and providing feedback to the students. The panel members were Hassan Gomaa (George Mason University), Jörg Kienzle (McGill University), Dorina Petriu (Carlton University) and Claudia Pons (Universidad Nacional de La Plata).

Gabriela Arévalo

Robert Pettit

MoDELS 2006 Doctoral Symposium Co-Chairs 